\title{
O DIREITO COMO MITO: A RAZÃO PUNITIVA E A INVENÇÃO DO DIREITO FUNDAMENTAL A SEGURANÇA PÚBLICA
}

Raphael Boldt ${ }^{1}$

João Maurício Adeodato²

\author{
"O mito jáé esclarecimento e o esclarecimento \\ acaba por reverter à mitologia."
}

\section{Resumo}

As premissas antropológicas iluministas evidenciaram uma imagem negativa do homem, resultando na conhecida formulação hobbesiana de que "o homem é o lobo do homem". Assim, o direito moderno, em especial o direito penal, deveria desempenhar um papel importante na limitação e no controle da liberdade humana ameaçadora. Desenvolvida a partir do método dialético, conforme a perspectiva da teoria crítica de matriz frankfurtiana, a pesquisa se propõe a enfrentar as seguintes questões norteadoras: qual a relação entre a razão punitiva e o direito fundamental à segurança? Qual o papel desempenhado por essa relação na ressignificação dos direitos fundamentais e do Estado na contemporaneidade? Para tanto, assume a hipótese de que a racionalidade subjacente à justiça penal moderna se desvinculou da liberdade como fundamento primordial e tem instrumentalizado atualmente uma figura jurídica artificial denominada "direito fundamental à segurança pública" com a finalidade de legitimar a existência do sistema penal, que, sob a justificativa de proteger o cidadão da violência de outros cidadãos, produz a perda da própria liberdade.

Palavras-chave: Mito. Sistema Penal. Razão Punitiva. Direitos Fundamentais. Segurança Pública.

\footnotetext{
${ }^{1}$ Doutor em Direitos e Garantias Fundamentais pela Faculdade de Direito de Vitória (FDV), com estágio doutoral na Johann Wolfgang Goethe-Universität (Frankfurt am Main). Professor nos cursos de Graduação e Pós-Graduação da Faculdade de Direito de Vitória (FDV).E-mail: raphaelboldt@hotmail.com

2 Professor da Faculdade de Direito de Vitória (FDV). Pesquisador 1 A do CNPq. Mestre. Livre Docente pela Faculdade de Direito da Universidade de São Paulo (USP). Pós-Doutorado pela Fundação Alexander von Humboldt. Professor Titular Aposentado da Faculdade de Direito do Recife (UFPE).E-mail: jmadeodato@gmail.com

${ }^{3}$ HORKHEIMER, Max; ADORNO, Theodor. Dialética do esclarecimento: fragmentos filosóficos. Rio de Janeiro: Jorge Zahar, 1985, p. 15.
} 


\section{INTRODUÇÃO: A INVENÇÃO DO DIREITO E AS PROMESSAS DA MODERNIDADE}

A concepção grega clássica da história recusa tanto concepções etiológicas, que veem sucessões de causas e efeitos nos eventos, quanto escatológicas, que pretendem descobrir "leis" que permitiriam prever desenvolvimentos futuros, provocando a ilusão de "progressos" históricos. A visão dominante na historiografia parece advir da mentalidade cartesiana e dos aparentes sucessos da ciência moderna no domínio da natureza, perspectiva que já dá sinais de esgotamento nos resultados predatórios de tal atuação. Nietzsche ensina que os processos históricos não se deixam prever, vez que "todos os conceitos nos quais se compõe semioticamente um processo inteiro escapam à definição; definível é somente aquilo que não tem história" (NIETZSCHE, 1988, p. 245-424). ${ }^{4}$

Ele procura assim recusar a tradição mitológica e os atrativos escatológicos da filosofia da história de Hegel, divinizada, que despreza o caráter único dos eventos reais, arguida por Heráclito, e ironiza: mas esse Deus tornou-se, no interior da caixa craniana de Hegel, transparente e inteligível para si mesmo e já galgou os degraus possíveis de seu vir a ser, até chegar a essa auto-revelação [...]. Porque esse equivocado espírito "absoluto", que a tudo sintetiza,

[...] transforma todos os momentos em simples admiração pelo sucedido e conduz à idolatria do factual: culto este para cujo serviço todos se exercitaram na formulação, muito mitológica e além disso bem alemã, de 'render-se aos fatos'. Se todo sucedido contém em si uma necessidade racional, se todo acontecimento é o triunfo do lógico ou da 'ideia' [...]. (NIETZSCHE, 1988, p. 308 e 309$)^{5}$

A história do direito tem sido considerada, frequentemente, como uma luta progressiva contra a irracionalidade, motivo pelo qual, na sociedade moderna, o sistema de justiça penal deveria conduzir, desde a sua gênese, a um tratamento condizente com a própria condição do homem como ser racional, livre e igual. Possível, portanto, neste quadro, concordar com Salo de Carvalho (2015, p. 04) no sentido de que as ciências criminais foram direcionadas a anular a violência do bárbaro e afirmar os ideais dos civilizados, mas produziram seu oposto ao longo do processo de constituição (e crise) da Modernidade, ou seja, "colocaram em marcha tecnologia formatada pelo uso desmedido da força, cuja programação, caracterizada pelo alto poder destrutivo, tem gerado inominável custo de vidas humanas".

\footnotetext{
${ }^{4}$ „Alle Begriffe, in denen sich ein ganzer Prozess semiotisch zusammenfasst, entziehen sich der Definition; definirbar ist nur Das, was keine Geschichte hat."

5 „Dieser Gott aber wurde sich selbst innerhalb der Hegelischen Hirnschalen durchsichtig und ver- ständlich und ist bereits alle dialektisch möglichen Stufen seines Werdens, bis zu jener Selbstoffenba- rung emporgestiegen: ...” „....llle Augenblicke in nackte Bewunderung der Erfolges umschlägt und zum Götzendienste des Thatsächlichen führt: für welchen Dienst man sich jetzt die sehr mythologische und ausserdem recht gut deutsche Wendung ,den Thatsachen Rechnung tragen' allgemein eingeübt hat." E logo adiante: „Enthält jeder Erfolg in sich eine vernünftige Nothwendigkeit, ist jedes Ereigniss der Sieg des Logischen oder der ,Idee'...”.
} 
Em detrimento da emancipação humana e da concretização dos direitos e garantias fundamentais, fontes de emancipação elaboradas pelo imaginário jurídico moderno, a política criminal fez a justiça penal abandonar a "razão do direito" (LÜDERSSEN , 1988, p. 325), a ponto de Steinert (1989, p. 35) afirmar que as políticas criminais sempre tiveram a sua cota de irracionalidade, derivadas dos seguintes pressupostos assumidos pelo sistema penal:

a) La cantidad de 'delitos' puede reducirse haciendo algo a las personas que hayan cometido o puedan cometer actos considerados como tales; b) La ley penal es un instrumento adecuado y efectivo para hacerlo. Esto implica también que el estado - o en general alguna autoridad central - es principal o exclusivamente responsable de la política criminal; c) La pena, es decir, el hacer algo desfavorable a las personas antes mencionadas, es el medio apropiado y efectivo.

Essas hipóteses irracionais resultam da própria racionalidade instrumental que conforma a "razão punitiva" (SCHEERER, 2001, p. 69-83) ${ }^{6}$ moderna e atuam como substrato para a construção do sistema penal, reprodutor de uma realidade que, do ponto de vista dos vencidos da história, pode ser configurada como catastrófica, categoria que Benjamin (1991) compreende como constitutiva do progresso.

Questão central a ser percebida é que, embora para a filosofia do iluminismo a liberdade tenha assumido uma posição central, a ponto de legitimar o Estado moderno, historicamente o desejo de segurança absoluta propiciou o surgimento do terrorismo de Estado, o que levou Albrecht (2010, p. 152) a considerar como anacrônica a atual reivindicação de um "direito fundamental à segurança". Sendo assim, o principal objetivo deste trabalho funda-se na tarefa de investigar as relações entre a razão punitiva e o direito fundamental à segurança pública, de modo a explicitar o papel desempenhado por essa relação na ressignificação dos direitos fundamentais e do Estado na contemporaneidade.

Diante da previsibilidade de um conflito violento generalizado, decorrente do uso descontrolado da liberdade, tornou-se necessário desenvolver estratégias capazes de evitar esse estado perigoso para os seres humanos; o direito moderno seria então a saída para esse dilema apresentado pela doutrina do estado de natureza, de maneira que o direito penal desempenharia um papel importante na limitação e no controle de uma ameaçadora liberdade humana desenfreada (ALBRECHT, 2010, p. 156).

Núcleo do ideário filosófico iluminista, o contrato social foi criado com a finalidade de garantir a liberdade pessoal dos indivíduos e superar o perigoso estado de natureza. Com a renúncia recíproca à violência e sua transferência para um terceiro supostamente neutro, funda-se o Estado moderno, responsável pelo confisco do conflito e por pacificá-lo por meio do monopólio legítimo da violência. Eis aí o direito como mito.

Este trabalho se propõe, portanto, a enfrentar as seguintes questões: qual a relação entre a razão punitiva 
e o direito fundamental à segurança? Qual o papel desempenhado por essa relação na ressignificação dos direitos fundamentais e do Estado na contemporaneidade? Nesse sentido, assume a hipótese de que a racionalidade subjacente à justiça penal moderna se desvinculou da liberdade como fundamento primordial e instrumentaliza atualmente uma figura jurídica artificial denominada "direito fundamental à segurança pública" com a finalidade de legitimar a própria existência do direito penal e a adoção de políticas criminais irracionais, que, sob a justificativa de proteger o cidadão da violência de outros cidadãos, produz a perda da própria liberdade; a nosso ver, a legitimação filosófica da outorga de liberdade pelo Estado é frágil, especialmente a partir de uma análise empírica da história de violações à liberdade relacionadas à atuação estatal. A simbiose proveniente de uma antropologia que se funda em uma atitude de desconfiança e receio nas relações intersubjetivas e otimismo excessivo no tocante ao poder exercido pelo Estado fragiliza o reconhecimento recíproco e potencializa a tendência do poder punitivo em ultrapassar os limites estabelecidos pela legalidade.

Por fim, a utilização do método dialético ${ }^{7}$ parece uma escolha adequada, sobretudo diante da realização de uma investigação que se propõe a um olhar essencialmente crítico sobre o objeto de estudo selecionado: a tensão existente entre a racionalidade do moderno sistema de justiça penal, supostamente criado para elaborar uma tecnologia (racionalidade instrumental) direcionada ao progresso e ao avanço social e a deterioração dos direitos fundamentais a partir da invenção do direito fundamental à segurança que serve de fundamento para o próprio direito penal.

\section{A PERSPECTIVA DOS "CIVILIZADOS": O SISTEMA DE JUSTIÇA CRIMINAL A PARTIR DA NARRATIVA ILUMINISTA}

Ao estudarmos as sociedades tribais quase sempre corremos o risco de realizar uma análise comparativamente depreciativa e pautada por preconceitos que levam ao exotismo e à inferiorização daqueles povos que, desde a perspectiva dos "civilizados", carecem de dignidade e até mesmo de história. Para Hegel, filósofo que "inaugurou o discurso da modernidade" (HABERMAS, 2000, p. 73), a história depende da própria existência do Estado, ou seja, "é o Estado que apresenta em primeiro lugar o assunto que não é apenas adequado à

\footnotetext{
${ }^{6} \mathrm{O}$ conceito foi amplamente desenvolvido por Scheerer no mencionado artigo e será empregado aqui para referir-se à "racionalidade subjacente à justiça penal moderna". PIRES, Álvaro. A racionalidade penal moderna, o público e os direitos humanos. Novos Estudos Cebrap, n. 68, pp. 39-6, 2004.

${ }^{7}$ A dialética assume, em conexão com o pensamento frankfurtiano, seu caráter incompleto e inacabado; uma "dialética aberta" que reconhece as persistentes tensões entre teoria e realidade e a necessidade de constantemente redefinir-se ao travar contato com o objeto de pesquisa. Fazemos referência, portanto, à "dialética moderna” na qual se inserem os autores da primeira geração da Escola de Frankfurt, a qual trabalha, implícita ou explicitamente com as figuras lógicas elementares das "antinomias estritas", conforme referido por Ritsert em sua obra. A respeito, conferir: RITSERT, Jürgen. Themen und Thesen kritischer Gesellschaftstheorie: Ein Kompendium. Weinheim und Basel: Beltz Juventa, 2014, p. 86.
} 
prosa da história, mas que a cria junto com ele” (HEGEL, 2001, p. 112), de modo que a mera história dos indivíduos ainda não pode ser concebida como tal. Na visão de Hegel, a palavra história, em alemão Geschichte, proveniente de geschehen (acontecer), combina os lados objetivo e subjetivo. Assim, história significa ao mesmo tempo a historiam reruin gestarum e a res gestas: os acontecimentos e a narração dos acontecimentos, linguagem e metalinguagem.

Se a filosofia hegeliana apresenta o Estado como condição da história e universo da liberdade individual, cuja concretização só é possível no âmbito de uma cultura nacional, a narrativa contratualista buscou institucionalizar e legitimar o poder por meio do contrato social, um pacto estabelecido entre os homens isolados no estado de natureza com a finalidade de constituir um corpo político que pudesse evitar a desestabilização das relações intersubjetivas e consolidar a segurança e a tranquilidade necessárias à preservação da propriedade. Essa narrativa pode ser extraída, por exemplo, do pensamento de John Locke (2005), para quem o homem tem, por sua natureza, o poder não apenas de preservar sua propriedade - isto é, sua vida, sua liberdade e seus bens - contra o agravo de outros homens, mas também de julgar e punir violações da mesma por outros, até mesmo com a morte, se necessário. Como se pode perceber, a naturalização de alguns direitos produziu a normalização do poder punitivo, cujo exercício se justificaria a partir de uma base ontológica, apoiada na convicção de que haveria normas válidas em si mesmas e, como tal, acima do direito positivo.

Embora o pensamento iluminista dominante tenha sido duramente criticado por Hegel, para quem a ideia de sociedade civil era muito mais ampla e não possuía natureza contratual, as formulações oriundas da filosofia política contratualista têm sido apresentadas como expressão do desenvolvimento da liberdade individual na modernidade e se transformaram em "relatos (temporariamente) vencedores" (ADEODATO, 2010, p. 78). A influência dessa filosofia no constitucionalismo moderno dificilmente será exagerada.

Os contratualistas preocupam-se com o trinômio sociedade civil, Estado e governo. Em Rousseau, Locke e mesmo no chamado absolutismo de Hobbes, o poder emana de um contrato ideal do qual fazem parte todos os cidadãos, em pé de igualdade.

O critério para o direito justo não deve ser procurado no direito positivo (por isso são ainda jusnaturalistas), nem nas maiorias circunstanciais que o sistema one man, one votepode produzir. Assim, apelam a instâncias como a "Vontade Geral" de Rousseau, a qual deve guiar as escolhas éticas sem confundir-se com a vontade da maioria, a qual vai triunfar com o positivismo que domina a sociedade complexa por sua eficiente flexibilidade em relação aos conteúdos éticos.

Para Jean-Jacques Rousseau (1762, Ch. VII) o ser humano traz direitos subjetivos do estado de natureza, os quais o Estado, por ser a outra parte no contrato social, deve respeitar e proteger. Esses direitos dos cidadãos limitam a ação do Estado: 
Vê-se por essa fórmula que o ato de associação encerra um engajamento recíproco do público com os particulares e que cada indivíduo, firmando um contrato, por assim dizer, consigo mesmo, encontra-se engajado sob uma dupla relação, a saber, como membro do soberano diante dos particulares e como membro do Estado diante do soberano. ${ }^{8}$

Hobbes nesse sentido é mais moderno: o direito do Estado deve prevalecer, já que não é parte do contrato social, mas sim seu resultado: os cidadãos são as partes que o constituem por contrato, cedendo-lhe todos os seus direitos naturais.

Tenta assim justificar e legitimar racionalmente o poder do Estado, abdicando de explicações religiosas sobre a "origem" do Estado, a sua razão de ser. O Estado, ao qual Hobbes (2000, p. 11) se refere como o "grande Leviatã", um "homem artificial", foi instituído essencialmente para a proteção e a defesa dos cidadãos, sendo os castigos e recompensas os "nervos" que cumprem as mesmas funções no corpo natural. Nesse sentido, a missão do soberano "não é outra senão obter a segurança do povo" (HOBBES, 2000, p. 239).

Enquanto para Hobbes o poder soberano deveria ser absoluto, isto é, ilimitado, Locke, como Rousseau, sustentavam a manutenção dos direitos naturais dos homens, indispensáveis para a limitação do poder soberano. Se em suas análises compartilham do homem no estado de natureza, antes de qualquer sociabilidade, com Locke a atuação do poder soberano encontra limites que não foram impostos por Hobbes. Criado para proteger os direitos naturais, sobretudo a propriedade, o Estado utiliza o poder punitivo para castigar aqueles que violam o contrato. Ao consentir com a transferência de parcela de sua liberdade para o soberano, os indivíduos assumem que eventuais transgressões aos seus direitos não atingem apenas a vítima, mas também a sociedade. Nesse contexto, o poder punitivo, aparentemente racional e secularizado, se torna imprescindível e a pena afigura-se como uma reação legítima com o objetivo de preservar o pacto social.

Com os filósofos iluministas, a concepção contratual da sociedade civil forjou os alicerces da "humanização" do sistema penal, renunciando, no plano discursivo, às arbitrariedades do Estado absoluto. A garantia dos direito naturais dos indivíduos, sobretudo da propriedade, contra os abusos estatais, levou à elaboração do direito penal moderno, caracterizado pela imposição de rígidos limites (princípio da legalidade) ao poder punitivo estatal e pela racionalização subjacente ao processo de desmistificação supostamente libertário que Weber (2004) chamou de "desencantamento do mundo", responsável pelo afastamento das imagens religiosas e pela criação de uma cultura profana.

Se por um lado a crítica de Hegel aos contratualistas propiciou a reflexão sobre as limitações decorrentes de um paradigma que restringira a existência do Estado a um contrato, não mais sujeito às vontades arbitrárias e instáveis dos indivíduos, por outro, ela disseminou a ideia do Estado racional -"encarnação substantiva da

\footnotetext{
8 "Du Souverain - On voit par cette formule que l'acte d'association renferme un engagement réciproque du public avec les particuliers, et que chaque individu, contractant, pour ainsi dire, avec lui-même, se trouve engagé sous un double rapport; savoir, comme membre du souverain envers les particuliers, et comme membre de l'État envers le souverain."
} 
racionalidade e espaço apropriado à plenitude da vida moderna da humanidade" (MORRISON, 2006, p. 199) e conferiu pretensão racionalista à sanção penal, concebida como uma exigência ética, implicitamente justa e capaz de restaurar o equilíbrio perdido em virtude da prática delituosa. Ao tratar o crime como negação do direito e manifestação de uma vontade irracional, Hegel sugere que a coerção configura-se como a negação capaz de reestabelecer a vontade geral, ou seja, a ordem jurídica violada. O castigo penal é apresentado, assim, como a razão do direito e, mais do que isso, um direito do próprio criminoso que, ao ser punido, é reverenciado como um ser racional.

omo se pode notar, assim como as propostas contratualistas, a filosofia de Hegel constituiu a retórica dominante na história ocidental. Ao definir a realidade a partir da história e indicar o Estado como pré-requisito desta, Hegel inviabilizou a própria história para além do Estado, o alfa e o ômega, e fundamentou o que Cassirer (1946, p. 263) considera um "novo tipo de absolutismo". O desencantamento moderno sucumbe, desta forma, diante de um conhecimento que se transforma em mitologia e fornece os fundamentos para a construção da imagem mítica de um Estado que é a concretização da ideia ética, do poder lógico de Deus.

Embora Hegel seja suscetível a muitas interpretações e o desenvolvimento do direito e do Estado racional seja o centro da sua teoria social, o poder punitivo é a chave para compreender a civilização técnicocientífica que instrumentaliza o Estado e ratifica o confisco do conflito. Nesse sentido, Zaffaroni (2003, p. 557) afirma que o pensamento hegeliano "não se afasta muito da contradição básica do direito penal liberal em sua versão fundacional: debate-se entre legitimar e pôr limites". Assim como fizeram os contratualistas, "legitima por um lado, enquanto o limite alça voo rumo à utopia”.

\section{O ESTADO MODERNO E A RETÓRICA DO DIREITO FUNDAMENTAL A SEGURANÇA PÚBLICA}

Hegel desenvolveu sua teoria sobre o Estado a partir de uma crítica à tradição jusnaturalista dos filósofos contratualistas. A concepção hegeliana se opõe à hipótese do homem em estado de natureza e à concepção de que a sociedade é composta por indivíduos isolados que, por meio de um pacto, formaram o Estado com o objetivo de garantir a liberdade individual e a propriedade privada.

Na filosofia política de Hegel, o Estado funda a sociedade, de modo que seria um equívoco defender, como o fizeram as teorias contratualistas, a anterioridade dos indivíduos. A ideia do homem em estado de natureza não se sustenta, pois o homem é desde sempre um indivíduo social. Segundo a dialética hegeliana, o Estado representa a totalidade dos interesses contraditórios entre os indivíduos, a síntese que supera a contradição 
entre o público e o privado.

Conforme mencionamos anteriormente, a filosofia política de Hegel exerceu grande influência no desenvolvimento do pensamento político moderno e engendrou interpretações diversas. Representante dos chamados hegelianos de esquerda, Engels (2000, p. 191) não concebe o Estado como a realidade da ideia moral ou da razão, mas como "produto da sociedade, quando esta chega a um determinado grau de desenvolvimento", resultado de uma contradição irremediável e de antagonismos que a própria sociedade não consegue conjurar. Numa tentativa de impor limites a esses antagonismos e impedir que classes com interesses econômicos colidentes se destruam, surge o Estado como um poder nascido da sociedade, mas acima desta.

Para Engels, diferentemente da perspectiva hegeliana, o Estado não supera as contradições da sociedade civil, mas se configura como o reflexo de tais antagonismos. Mais do que isso, em vez de superar as contradições da sociedade civil, o Estado acaba por perpetuá-las e é exatamente por isso que, em algum momento da história, o Estado deverá desaparecer.

Sob o risco de incorrermos em excessivas simplificações, não pretendemos aqui esboçar ou sistematizar as inúmeras teorias que marcaram o desenvolvimento do pensamento político moderno, somente perquirir as relações entre o Estado moderno e o direito fundamental à segurança pública, invenções legitimadas, sobretudo, pelos filósofos contratualistas, cuja principal ficção, a teoria do contrato social, contribuiu para a elaboração de instrumentos de controle que pulverizam vários direitos humanos sob o pretexto de solucionar conflitos e estabelecer limites ao poder soberano. Nem a concepção marxista negativa do Estado, nem as críticas apresentadas por Hegel ao contratualismo minaram as bases do contrato social como núcleo do iluminismo. No campo penal, o que se percebe atualmente é a legitimação e expansão do poder punitivo estatal a partir da consolidação de uma espécie de simbiose entre a onipotência oriunda do estado de natureza hobbesiano e a deificação do Estado proveniente de determinada interpretação da filosofia hegeliana.

Para solucionar o dilema do estado de natureza, da guerra de todos contra todos, foram inventados o Estado e o direito modernos. Nesse mesmo sentido, Albrecht (2010, p. 156) afirma que o contrato social é uma "invenção da liberdade", com a qual se pretende garantir a liberdade pessoal do indivíduo e superar o estado de natureza. De tal ficção iluminista deriva, portanto, o "monopólio da violência legítima" atribuído ao Estado, sociologicamente definível por "um meio específico que lhe é próprio, como também a toda associação política: o da coação física" (WEBER, 1999, p. 526). Com o contrato social e a fundação do Estado, outro invento se fez necessário: o direito penal.

Segundo Scheerer (2001, p. 69-83), a apresentação da normalidade, senão da naturalidade da pena, constitui o pilar mais importante de sustentação da própria pena e do direito penal, de modo que, "para a sabedoria popular, essas ideias parecem 'eternas' ou constituem um passo importante rumo ao 'progresso'” 
(STEINERT, 1989, p. 36) ${ }^{9}$, categoria que, desde a crítica romântica benjaminiana, identifica-se com a própria barbárie.

Ao mencionarmos a "invenção" do direito penal, o fazemos, conforme Hobsbawm (1997, p. 10), para denunciar uma continuidade artificial em relação ao passado histórico. No mesmo sentido das "tradições inventadas", o Estado e o direito penal apresentam-se como "reações a situações novas que assumem a forma de referência a situações anteriores, ou estabelecem seu próprio passado através da repetição quase que obrigatória”. Como produto cultural, o direito penal não tem origem, mas foi fabricado, inventado por obscuras relações de poder que, para Nietzsche (1988), nada têm a ver com a natureza humana.

Embora a liberdade legitime o Estado moderno e o direito penal tenha sido imaginado para limitar e controlar "uma ameaçadora liberdade humana desenfreada" (ALBRECHT, 2010, p. 156), a história mostra que a invenção tem se voltado contra os seus criadores, levando, com isso, à perda de legitimidade do Estado. Recentemente, outra "figura jurídica artificial" (ALBRECHT, 2010, p. 164) foi criada e substituiu o fundamento do Estado moderno. Com a finalidade de proteger o cidadão da violência de outros cidadãos, o "direito fundamental à segurança pública" rejeita a liberdade como pedra de toque do Estado e confere à segurança papel central.

Esse papel guarda forte relação com a função do direito e a angústia humana diante do futuro e da morte, pedra de toque da filosofia existencialista e também da visão de Luhmann (1972, p. 31, ss.) sobre o controle das expectativas, ao dizer que as normas "controlam o medo". As normas ordenam o futuro, controlam expectativas atuais sobre o futuro, que ainda não existe e é imprevisível, por isso sempre é possível descumprir ou cumprir as normas, mas elas nos garantem segurança.

Colocar a segurança como direito fundamental constitui uma ilusão altamente funcional ao exercício arbitrário do poder punitivo estatal, uma vez que a segurança seria um pressuposto que condiciona a própria existência do Estado a partir da fábula contratualista. Ora, qual seria então o sentido de atribuir à segurança o status de direito fundamental, se a função do Estado está exatamente em assegurar a paz e a defesa dos cidadãos? A segurança de garantia da liberdade dos indivíduos é o que justifica a criação deste "deus mortal", levando os homens a cederem os seus direitos ao soberano. Com a invenção do direito fundamental à segurança pública, mitos são conservados e impedem a emancipação pretendida pela filosofia iluminista. Entregues à sedução do canto das sereias, prolongamos nosso aprisionamento às origens míticas do Estado em nome da autoconservação e presenciamos a promessa da felicidade se dissolver ao preço da repressão e da razão.

\footnotetext{
9 "Para la sabiduría popular, estas ideas parecen 'eternas' o constituyen un paso importante hacía el 'progreso".
} 


\section{A NEGAÇÃO DA LIBERDADE E A REAFIRMAÇÃO DO MITO: DA EXALTAÇÃO DA RAZÃO PUNITIVA AO PODER ILIMITADO}

A atribuição do status de direito fundamental à segurança pública tem ganhado contornos ainda mais nefastos no contexto atual. Com a superposição da segurança em relação à tutela da liberdade, verificamos a ascensão daquilo que Albrecht (2010, p. 216) denomina "direito penal de segurança”, cujas principais características consistem na militarização da segurança pública interna e na invocação de sacrifícios especiais como dever do cidadão em prol da segurança total, algo tão ilusório quanto a própria ideia de um direito fundamental à segurança.

$\mathrm{O}$ anseio por medidas capazes de garantir a segurança plena de sociedades inteiras, ameaçadas pela violência que se manifesta em suas mais diversas e inesperadas formas (especialmente aquelas designadas como terrorismo), atua, inequivocamente, como elemento catalisador para a multiplicação de medidas de segurança que negam não apenas a liberdade, mas a legalidade, um dos mais importantes alicerces do Estado de Direito. Com o direito fundamental à segurança pública e o direito penal de segurança, aniquila-se o próprio Direito.

A erosão do Estado de Direito não é o único resultado perceptível a partir da consagração do paradigma securitário. As orientações globais por segurança produzem efeitos nos mais diversos campos, tanto em países centrais quanto na periferia. Evidentemente, os efeitos são os mais diversos possíveis, desde a autopropulsão do medo à apropriação da segurança para fins políticos e comerciais. Nas palavras de Bauman (1999, p. 125),

um bocado de tensão acumula-se em torno da busca por segurança. E onde há tensão os investidores espertos e corretores competentes com certeza reconhecerão um capital político. Apelos a medos relacionados à segurança estão verdadeiramente acima das classes e partidos.

Se para Freud (2010, p. 74) a troca de boa parcela da liberdade pessoal por certa medida de segurança coletivamente garantida pode ser apontada como a principal causa das aflições e sofrimentos psíquicos da civilização moderna, neste caso, o contrato social seria a gênese de parte considerável das patologias da modernidade. Em um mundo cada vez mais inseguro e incerto, a busca por segurança e certeza se transformou em verdadeira obsessão e razão de ansiedade. Com a invenção do direito fundamental à segurança verificamos a natureza ambígua do homem moderno que, seguindo o ritual de Tântalo, quanto mais se aproxima do seu objeto de desejo, mais inalcançável este se torna ${ }^{10}$.

Apesar de não pretendermos com este trabalho afirmar que o poder político ou a autoridade do Estado

\footnotetext{
${ }^{10}$ De acordo com a mitologia grega, Tântalo, por ofender os deuses, foi condenado a jamais saciar a fome e a sede, mesmo vivendo em um vale com vegetação e água abundantes. Quanto mais se aproximava dos frutos, mais eles se afastavam dele, levados pelo vento; ao tentar beber água, esta escoava para longe. O castigo de Tântalo era ver os seus objetos de desejo próximos, porém, inalcançáveis.
} 
sejam intrinsecamente nocivos, tampouco nos basearmos numa visão otimista ou pessimista da natureza inata do homem, assumindo claramente uma perspectiva negativa do poder e, portanto, um absoluto pessimismo em relação ao poder punitivo estatal. Ainda que a Teoria Crítica desenvolvida pela Escola de Frankfurt seja a principal matriz teórica utilizada na pesquisa, nos afastamos da "antropologia negativa" que estava na base dos estudos desenvolvidos por autores como Adorno e Horkheimer, aproximando-nos, neste caso, da visão agnóstica rousseuaniana compartilhada por Franz Neumann (JAY, 2008, p. 1999).

nvertemos, com isso, a lógica hobbesiana que originou e justificou o poder absoluto, ou seja, uma antropologia que se funda em uma atitude de desconfiança e receio nas relações intersubjetivas e otimismo excessivo quanto ao poder exercido pelo Estado. Assim, se por um lado o Estado não deve ser percebido como um mal em si, nem como a síntese capaz de superar as contradições da sociedade civil, o ser humano também não é naturalmente bom nem mau. Precisa de instituições, sim, estatais ou não, que lhe garantam uma vida gregária em que sejam desenvolvidas suas plenas capacidades e minimizados os inevitáveis conflitos.

Ao nos afastarmos dos extremos, o fazemos para evitar as consequências que acarretam. Se uma visão excessivamente otimista da natureza humana pode levar ao anarquismo, o pessimismo absoluto pode conduzir ao absolutismo. Eé exatamente aí que entra em cena a tentação autoritária que deteriora as democracias modernas. A crença na maldade inata do ser humano e na bondade do poder punitivo tem justificado a supressão de direitos e a expansão ilimitada do poder, antítese daquilo que apontamos como pressupostos que condicionam a existência das democracias, isto é, a domesticação da intolerância, o reconhecimento e a inclusão do outro e a fragmentação do poder (ADEODATO, 2010, p 116).

A despeito das críticas tecidas ao direito fundamental à segurança pública, não desconsideramos a utilidade de tal invenção, pois, como todo e qualquer mito, cumpre a importante função de preencher os vazios inerentes à teoria, afinal, "não há teoria sem vazios, nem há teoria sem mito" (CASARA, 2015, p. 329). Desde a perspectiva frankfurtiana, mais do que instrumento funcional ao saber, "o mito já é esclarecimento e o esclarecimento acaba por reverter à mitologia." (HORKHEIMER; ADORNO, 1985, p. 15)

O mito deve ser compreendido como uma reflexão sobre a natureza, isto é, uma maneira de indicar um nascimento, de explicar o presente e de evocar um futuro não tão distante. Tudo acontece com um objetivo claro, tudo tem significado e relação direta com a sociedade na qual o mito foi criado (HORKHEIMER; ADORNO, 1985). Para Adorno e Horkheimer, ao reduzir o mito a uma forma de conhecimento inferior, o esclarecimento se transformou em uma nova forma de mitologia, um instrumento de poder ainda mais destrutivo.

Mais do que apenas explicar a realidade como forma de conhecimento, o mito procura acomodar e tranquilizar o homem em um mundo assustador. Por meio de relatos hegemônicos, historicamente o mito controla e domina as pessoas, atuando, assim, como uma poderosa forma de dominação que, neste caso, orienta- 
se eficazmente pela invocação da racionalidade. O esclarecimento moderno conserva em si a forma mítica de explicar o mundo, não mais a partir do sobrenatural, mas por intermédio da razão e da ciência. Extremamente útil à racionalidade penal moderna, o recurso ao pensamento mítico oferece ao Estado os fundamentos para a ampliação dos seus poderes, reforçando, com isso, os caracteres autoritários da sociedade. Evidentemente, o pensamento mítico permanece na sociedade moderna não mais em sua forma primitiva, mas sob a forma do conhecimento racional.

Ainda que os mitos não sejam eternos e, portanto, contingenciais, "o saber que é poder não conhece nenhuma barreira, nem na escravização da criatura, nem na complacência em face dos senhores do mundo" (HORKHEIMER; ADORNO, 1985, p. 18). Assim como a exaltação da razão não foi capaz de guiar a humanidade à emancipação e à liberdade, mas assumiu o que considerava obscuro, o direito fundamental à segurança pública tem se tornado, progressivamente, um mecanismo eficiente de negação da liberdade e subordinação das pessoas ao poder. Como produto cultural e formação histórica, a racionalidade da ciência moderna - da qual fazem parte o direito e as ciências criminais - está inserida no projeto de modificação das estruturas sociais e manutenção da dominação que, sob os umbrais da liberdade, oculta a expansão do poder. Como "racionalidade da dominação" (HABERMAS, 1997, p. 49), a razão punitiva proporciona a racionalização da falta de liberdade do homem e demonstra a impossibilidade de determinar pessoalmente a sua vida. Na esteira de Marcuse (2015), a falta de liberdade não decorre da irracionalidade, mas da sujeição à razão que abre-se a uma sociedade totalitária de base racional.

\section{CONSIDERAÇÕES FINAIS}

A ideia de que a vida social se define em seu conceito fundamental como uma relação de luta por autoconservação entre sujeitos que se contrapõem e concorrem permanentemente entre si pode ser vista nos escritos políticos de Nicolau Maquiavel e Thomas Hobbes, tornando-se, na obra deste último, "a base de uma teoria do contrato que fundamenta a soberania do Estado" (HONNETH, 2003, p. 31). As premissas antropológicas que marcaram o início do Iluminismo evidenciam uma imagem negativa do homem, resultando, com isso, na conhecida formulação hobbesiana de que o homem é o lobo do homem e que da natureza humana deveria resultar uma guerra ininterrupta de todos contra todos (HOBBES, 2000).

Diante da previsibilidade de um conflito violento generalizado proveniente do uso descontrolado da liberdade, foram inventadas estratégias capazes de impedir esse estado perigoso para a humanidade. Uma das criações destinadas a solucionar o dilema apresentado pela doutrina do estado de natureza foi justamente o direito moderno e, mais especificamente, o direito penal, responsável por fornecer mecanismos de controle e limitação de 
uma suposta liberdade humana desenfreada e ameaçadora à existência.

Vale notar que a renúncia recíproca à violência e sua transferência para um terceiro presumidamente neutro viabilizaram a invenção do Estado moderno. Ao confiscar o conflito, o Estado deveria pacificá-lo por meio do monopólio legítimo da violência. A partir da narrativa moderna de que o campo da ação social consiste numa luta permanente de sujeitos egocêntricos pela conservação de sua identidade física, a teoria do contrato social ofereceu os aportes teóricos necessários para a criação do direito penal moderno e do Estado de Direito, no qual prevalece um poder limitado e, portanto, legítimo, que só pode ser exercido em caso de violação à liberdade. Como se pode perceber, o mito está na própria origem do direito moderno.

Para Adorno e Horkheimer (1985) a modernidade apenas aprofundou as raízes do iluminismo, firmadas desde a antiguidade. Esse aprofundamento engendrou a razão instrumental e tornou o homem descrente dos mitos tradicionais, levando-o ao mito da ciência moderna, num autêntico processo de deificação da ciência. Com a formação do Estado moderno, verificamos a definição do perfil do direito penal a partir de uma racionalização progressista que, para Horkheimer (2002, p. 08), tende a obliterar a própria substância da razão em nome da qual se apoia a causa do progresso.

Essa perspectiva evidencia a tensão existente entre a racionalidade do moderno sistema de justiça penal, supostamente criado para elaborar uma tecnologia (racionalidade instrumental) direcionada ao progresso e ao avanço social e a deterioração dos direitos fundamentais a partir da invenção do direito fundamental à segurança que serve de alicerce para o próprio direito penal.

Por fim, resta claro que a racionalidade subjacente à justiça penal moderna se desvinculou da liberdade como fundamento primordial, instrumentalizando o "direito fundamental à segurança pública" com a finalidade de legitimar a própria existência do direito penal e a adoção de políticas criminais contrárias à materialização dos direitos humanos. Sob a justificativa de proteger o cidadão da violência de outros cidadãos, deteriora-se a própria liberdade e os postulados humanistas que, aparentemente, servem de base para o "direito penal esclarecido". Sendo assim, é certo dizer que a simbiose decorrente de uma antropologia que se funda em uma atitude de desconfiança e receio nas relações intersubjetivas e otimismo excessivo no tocante ao poder estatal favorece a fragilização do reconhecimento recíproco e potencializa a tendência do poder punitivo em ultrapassar os limites estabelecidos pela legalidade, minando, com isso, os alicerces do Estado de Direito.

\section{LAW AS A MYTH: THE PUNITIVE REASON AND THE INVENTION OF THE FUNDAMENTAL RIGHT TO PUBLIC SECURITY}




\section{Abstract}

The illuminist anthropological premises would indicate a negative image of the man, resulting in the well-known hobbesian formulation that "man is the wolf to man". Thus, modern law, especially criminal law, should play an important role in limiting and controlling the threatening human freedom. Developed from the dialectical method, according to the critical theory of the frankfurtian matrix, the research proposes to address the following guiding questions: what is the relation between punitive reason and the fundamental right to security? What is the role played by this relationship in the re-signification of fundamental rights and the State in contemporary times? Therefore, this research assumes that the rationality underlying modern criminal justice has been detached from freedom as its fundamental foundation and has now used an artificial legal figure called the "fundamental right to security" with the purpose of legitimizing the existence of the criminal system, which, under the justification of protecting the citizens from the violence of other citizens, produces the loss of one's freedom.

Keywords: Myth. Criminal System. Punitive Reason. Fundamental Rights. Public Security.

\section{REFERENCIAS}

ADEODATO, João Maurício. A retórica constitucional (sobre tolerância, direitos humanos e outros fundamentos éticos do direito positivo). São Paulo: Saraiva, 2010.

ALBRECHT, Peter-Alexis. Criminologia: uma fundamentação para o direito penal. Tradução de Juarez Cirino dos Santos e Helena Schiessl Cardoso. Rio de Janeiro: Lumen Juris, 2010.

BAUMAN, Zygmunt. Globalização: as consequências humanas. Rio de Janeiro: Jorge Zahar Editor, 1999.

BENJAMIN, Walter. Anmerkungen zu Seite 69I-704. In: TIEDEMANN, Rolf; SCHWEPPENHÄUSER, Hermann (Hrsg.). Walter Benjamin. Gesammelte Schriften: Aufsätze, Essays, Vorträge. 1. Aufl. Band I.3. Frankfurt am Main: Suhrkamp, 1991.

CARVALHO, Salo de. Antimanual de Criminologia. São Paulo: Saraiva, 2015. 
CASARA, Rubens R. R. Mitologia processual penal. São Paulo: Saraiva, 2015.

CASSIRER, Ernst. The Mith of the State. New Haven: Yale University Press, 1946.

ENGELS, Friedrich. A origem da família, da propriedade privada e do Estado. Rio de Janeiro: Bertrand Brasil, 2000.

FREUD, Sigmund. Civilization and its discontents. New York: W. W. Norton \& Company, 2010.

HABERMAS, Jürgen. O discurso filosófico da modernidade: doze lições. São Paulo: Martins Fontes, 2000. Técnica e ciência como “ideologia”. Lisboa: Edições 70, 1997.

HEGEL, Georg Wilhelm Friedrich. A razão na história: uma introdução geral à filosofia da história. São Paulo: Centauro, 2001.

OBBES, Thomas. Leviatã, ou, A matéria, forma e poder de um estado eclesiástico e civil São Paulo: Ícone, 2000.

HOBSBAWM, Eric. A invenção das tradições. Rio de Janeiro: Paz e Terra, 1997.

HONNETH, Axel. Luta por reconhecimento: a gramática moral dos conflitos sociais. São Paulo: Editora 34, 2003.

HORKHEIMER, Max; ADORNO, Theodor. Dialética do esclarecimento: fragmentos filosóficos. Rio de Janeiro: Jorge Zahar, 1985.

HORKHEIMER, Max. Eclipse da razão. Tradução de Sebastião Uchoa Leite. São Paulo: Centauro, 2002.

JAY, Martin. A imaginação dialética: história da Escola de Frankfurt e do Instituto de Pesquisas Sociais (19231950). Tradução de Vera Ribeiro. Rio de Janeiro: Contraponto, 2008.

LOCKE, John. Dois tratados sobre o governo. Tradução de Julio Fischer. São Paulo: Martins Fontes, 2005. 
LÜDERSSEN, Klaus. Über das Irrationale im Strafrecht. In: ZACZYK, Rainer; KÖHLER, Michael; KAHLO, Michael (Hrsg.). Festschrift für E. A. Wolff zum 70. Geburtstag am 1. 10. 1998. Springer Verlag: Berlin/Heidelberg, 1998.

LUHMANN, Niklas. Rechtssoziologie. Reinbeck bei Hamburg: Rowohlt, 1972.

MARCUSE, Herbert. O homem unidimensional: estudos da ideologia da sociedade industrial avançada. São Paulo: EDIPRO, 2015.

MORRISON, Wayne. Filosofia do Direito: dos gregos ao pós-modernismo. São Paulo: Martins Fontes, 2006.

NIETZSCHE, Friedrich. Genealogie der Moral - Eine Streitschrift, in COLLI, Giorgio - MONTINARI, Mazzino (Hrsg.): Friedrich Nietzsche Kritische Studienausgabe - in fünfzehn Bände, vol. 5. Berlin: Walter de Gruyter, 1988.

Von Nutzen und Nachteil der Historie für das Leben. Unzeitgemässe Betrachtungen II, in COLLI, Giorgio - MONTINARI, Mazzino (Hrsg.): Friedrich Nietzsche Kritische Studienausgabe - in fünfzehn Bände, vol. I. Berlin: Walter de Gruyter, 1988.

PIRES, Álvaro. A racionalidade penal moderna, o público e os direitos humanos. Novos Estudos Cebrap, n. 68, 2004.

RITSERT, Jürgen. Themen und Thesen kritischer Gesellschaftstheorie: Ein Kompendium. Weinheim und Basel: Beltz Juventa, 2014.

ROUSSEAU, Jean-Jacques. Du contrat social ou principes du droit politique. Amsterdam: chez Marc Michel Rey, 1762.

SCHEERER, Sebastian. Kritik der strafenden Vernunft. Ethik und Sozialwissenschaften. Hamburg: Lucius, n. 12, 2001, p. 69-83.

STEINERT, Heinz. Mas alla del delito y de la pena. In: HULSMAN, Louk et al. Abolicionismo penal. Buenos Aires: Ediar, 1989. 
WEBER, Max. A ética protestante e o "espírito" do capitalismo. Tradução de José Marcos Mariani de Macedo. São Paulo: Companhia das Letras, 2004.

Economia e sociedade: fundamentos da sociologia compreensiva. Brasília: Editora Universidade de Brasília, 1999.

ZAFFARONI, Eugenio Raul et al. Direito Penal Brasileiro I. Rio de Janeiro: Revan, 2003.

Trabalho enviado em 17 de junho de 2018

Aceito em 17 de setembro de 2018 